\title{
ATOS RETÓRICOS, TERRORISMO E MÍDIA: O MOVIMENTO DAS PAIXÕES
}

\author{
Luiz Antonio Ferreira*
}

\begin{abstract}
RESUMO: Os discursos se tecem a partir de um exterior constitutivo-o discurso do outro, o já-dito-e operam sobre dizeres presentes e dizeres que se alojam na memória. Nesse espaço, instaura-se a ação retórica. Essa operação discursiva implica um movimento de paixōes que se infiltra na estrutura profunda do texto e, pela ação da memória discursiva, sustenta os recursos argumentativos que garantem o acordo entre retor e auditório. Nesse sentido, no discurso midiático, a memória e a actio têm papel fundamental na anatomia e fisiologia do ato retórico, uma vez que constituem um universo performático que congrega, num contexto determinado de comunicação, os componentes emotivos, racionais e históricos que se disseminam tanto pela kinésica forma de apresentar as palauras, de gesticular), quanto pela proxêmica (modo de fazer a interação com o espaço). O propósito deste trabalho é refletir sobre a competência retórico-argumentativa na midia escrita e suas implicaçōes com a memória discursiva, o movimento das paixōes no texto e o terrorismo.
\end{abstract}

PALAVRAS-CHAVE: Retórica, argumentação, memória discursiva, paixōes, terrorismo.

\section{or sua dinamicidade, a linguagem em funcionamento põe
em relação sujeitos e sentidos, afetados por sua lingua,}

* Pontifícia Universidade Católica de São Paulo - PUC-SP. 
FerReira, Luiz Antonio. Atos retóricos, terrorismo e mídia: o movimento das paixões.

sua história e efetiva-se num complexo processo de constituição de discursos e de produção de sentidos. Desse modo, o discurso congrega inúmeros recursos persuasivos, mobilizados para a consecução de um determinado fim. Configuram-se, assim, os atos retôricos, que se consubstanciam em textos, sempre condicionados a algum contexto, pois envolvem uma situação retórica, isto é,

[...] um complexo de pessoas, eventos, objetos e relaçōes que poderia ser completa ou parcialmente removido, caso um discurso, introduzido na situaçāo, pudesse influenciar o pensamento ou a ação da audiência, de forma a promover uma modificaçāo positiva na exigência em questāo. (Bitzer, 1980: 24)

Esse é o esforço de qualquer retor e, em nossos dias, estampa-se com freqüência nos discursos midiáticos em geral, em função dos atentados terroristas que se disseminam pelo mundo. História, ética, moral e memória se interpenetram na constituição textual e movimentam as paixōes humanas.

O homem contemporâneo ê "bombardeado", diariamente, no espetáculo da notícia, por cenas também espetaculares que suscitam movimentos passionais em cada um e em todos: seqüestro de ônibus urbano no Rio de Janeiro e morte de uma professora; fome, pestes e miséria na África; cidades bombardeadas pelos aviōes da OTAN, na Iugoslávia; crianças palestinas friamente assassinadas por tanques israelenses. A lista é longa e poderia, no decurso do tempo, incluir o terror politico: milhares de pessoas mortas sob as ordens de ditadores militares na América Latina; milhōes de civis mortos no Vietnã, no Camboja e em Laos, sob o bombardeio ininterrupto do exército dos Estados Unidos; destruição de Hiroxima e de Nagasáqui, também por bombardeio; mortes incontáveis em Auschwitz... No caso do discurso sobre o terror, o pathos toca a mola dos afetos e, assim, assegura a passionalidade do ouvinte, pois, como diz Aristóteles, as paixōes são "tudo o que faz variar os juizos, e de que se seguem sofrimento e prazer". Invocada pelo processo discursivo, a memória traz à tona as cenas vistas e alguma forma de 
Rev. ANPOLL, n. 14, p. 57-76, jan./jun. 2003.

movimento passional se manifesta em cada um de nós, pois a paixão se revela onde há mobilidade, onde há imperfeiçāo ontológica. Os efeitos discursivos em maior ou menor grau de passionalidade, por sua vez, são obtidos por estratégias retóricas.

Ressalte-se que, nessa situação retórica, os terroristas achamse no pleno direito de impingir o terror e, desse modo, criam tensāo. Entretanto, oferecem um espetáculo de ousadia, coragem e nenhum respeito humano. Como explicar essa atitude? O homem constrói sua identidade na relação dināmica com a alteridade e, de um modo ou de outro, assimila o movimento das crenças e paixões que movem seu grupo cultural. O texto, lugar da interação, dramatiza essa relação. Nesse processo, a tematização da morte, por exemplo, suscita uma reflexāo que, inevitavelmente, envolve sentidos advindos de outros discursos (animados por alguma intenção), situados em contextos históricos, sociais e afetivos em que o auditório se insere ou conheceu por herança. O resultado são efeitos de sentido. Grosso modo, o homem teme a morte, assim como todos os males que possam simbolizá-la, antecipá-la, recordá-la aos mortais, como bem reflete Marilena Chauí (2002: 37). Entretanto, como veremos no texto que analisaremos, há grupos suicidas, há grupos que vêm a morte como prêmio. Nesse universo tensivo atuam discursos divergentes que ampliam a tensão e envolvem o auditório num clima altamente emocional. É o mundo da doxa que se manifesta.

Um ato retórico, diante de um impasse dessa natureza, pode apelar para argumentos lógicos que procurem mudar atitudes e comportamentos, mas pode, sobretudo, explorar valores e anseios universais que pretendam incentivar atitudes humanas e humanizadoras e, pela constituição discursiva, consigam tocar a alma do ouvinte. Em um e outro caso, o retor, em busca da eficácia de seu discurso, explora, em maior ou menor grau, três objetivos da retórica: instruir (docere), comover (movere) e agradar (delectare). O discurso persuasivo, contido no ato retórico, pretende agir sobre o outro por meio do logos (palavra e razão), mas o estabelecimento de 
Ferreira, Luiz Antonio. Atos retóricos, terrorismo e mídia: o movimento das paixöes.

acordos com o auditório implica a disposição que os ouvintes conferem aos que falam (ethos). A reação desencadeada nos que ouvem (pathos) depende, então, da escolha dos argumentos e da credibilidade do retor. Assim, se considerarmos a ação retórica instaurada em um espaço, aqui visto como modo pelo qual a sociedade não somente reflete sobre si mesma, como reflete o que essa sociedade é, num tempo específico e marcado ideologicamente e que os discursos se tecem a partir de um exterior constitutivo - o discurso do outro, o já-dito - e operam sobre outros discursos, sobre dizeres presentes e dizeres que se alojam na memória e no espaço do dizer, essa operação discursiva infunde ao texto um movimento de paixões que coloca em consonãncia, pela ação da memória discursiva, uma seleção léxico-gramatical específica e põe em funcionamento os recursos argumentativos, a fim de garantir a adequação ao espaço social em que o retor atua. Para entender, de algum modo, os mecanismos que traduzem esse dizer é necessário envolver-se num processo de leitura do verbal da mídia, não só para traduzi-lo, como também para refletir sobre as instâncias retóricas que, imbricadas no processo discursivo, resultam em persuasão ou convencimento.

Em resumo, se em qualquer atuação lingüístico-discursiva sempre foi essencial a utilização da inventio, dispositio e elocutio para bem mover os auditórios, hoje, não é sem razão que, no mundo tecnológico, revigora-se, no ato retórico, o papel fundamental da memória e da actio, uma vez que constituem um universo performático que congrega, num contexto determinado de comunicação, componentes emotivos, racionais e circunstâncias ainda impactantes de uma determinada notícia. No caso dos ataques terroristas, por exemplo, uma mescla simultãnea de esperança de paz, medo e desespero se dissemina pelas diversas comunidades humanas e instaura um estado de espírito que precisa ser traduzido em discursos, quer como elemento catártico quer como pretexto para reflexōes mais densas. Em função disso, neste trabalho, refletimos sobre o papel da mídia escrita, sua competência retórico-argumentativa e suas 
Rev. ANPOLL, n. 14, p. 57-76, jan./jun. 2003.

implicações com a memória e a interação do "espaço" discursivo e figurativo do terror por acreditarmos que é necessário pensar a questāo da leitura, da retórica, da ação, da memória e suas relaçōes com o homem do século XXI, os meios de comunicação de massa e o terror. Esse, pois, será o caminho para nossa reflexão.

\section{O espaço midiático e a persuasão}

$\mathrm{Na}$ tentativa de informar, agradar e comover, os meios de comunicaçāo de massa instauram situações retóricas e praticam atos retóricos. Valem-se da linguagem para promover mudanças, para reforçar percepçōes, sentimentos, valores, posicionamentos e açōes. Por meio da linguagem, acirram as diferenças, reforçam as identidades, solidificam grupos que, por sua vez, defendem ferranhamente suas posições, crenças e o direito de estar no mundo. Nesse universo repleto de facções e interesses divergentes, a retórica é estimulada. Como bem reflete Burke (1969: 22), "o identificar-se compensa o estar dividido. Ponham-se identificação e divisão ambiguamente juntas, de modo a não se saber onde uma termina e onde a outra começa e temos o característico estímulo à retórica". Burke discursa sobre o dilema da convivência humana e, em função disso, considera a existência de uma "situação retórica universal" que, por meio da comunicação, da interação simbólica atua sobre os homens. Esse impulso retórico se traduz na actio, a última das operações do mo delo retórico, o culminar do processo textual-comunicativo que se dá com a atualização do discurso para um auditório que, por sua vez, deverá tomar uma decisão a propósito dos fatos que são objetos desse mesmo discurso.

Nesse sentido, há mesmo um discurso da paixão: verbalizamse ou provocam-se comumente paixões como medo, terror, horror, desorientação, vingança, confiança, desconfiança, coragem, desarranjo, desdém, esperança, indignação, desapontamento, rạcor, 
FERREIRA, Luiz Antonio. Atos retóricos, terrorismo e mídia: o movimento das paixões.

satisfação, gravidade, serenidade, calma e tensão imersos no processamento textual que, por sua vez, se tece por meio de estratégias sociocognitivas. Segundo van Dijk; Kintsch (1983), tais estratégias são do tipo procedural, isto é, valem-se de vários tipos de conhecimento que temos armazenados na memória. O autor então suscita o conhecimento e, quando lemos ou ouvimos um texto, construímos, na memória episódica, uma representação textual, definida em termos de conceitos e proposiçōes. A partir daí, construímos um modelo episódico de situação sobre o qual o texto versa. Compreensão e coerência, nesse sentido, são subjetivas e variáveis. No processo discursivo, o retor conta com a "disposição" do auditório para racionalizar o conteúdo. Contudo, não despreza a competência dos ouvintes para apaixonar-se e, assim, explora uma dimensão passional - constitutiva do discurso - que se consubstancia por meio de um ato retórico: uma tentativa intencional, criada e elaborada para superar obstáculos numa dada situação, com uma audiência específica, sobre determinada questão, para conseguir um determinado objetivo (Campbell, 1982: 7).

Desse modo, oscilando entre o racional e o passional, os meios de comunicação de massa tanto reforçam a paz quanto acirram a guerra. Fazem sua parte. Ao leitor compete a reflexão e o estudo dos mecanismos argumentativos que sustentam as opiniōes jornalísticas, já que numa concepção ampla, a retórica equivale a ụma determinada definição da realidade e, num sentido especifico, ao conjunto de recursos utilizados para propor essa visão. Não é, portanto, simplesmente techné a exigir cultivo e arte, mas uma visão da vida que implica tomada de posição, ação no mundo.

O ambiente de comunicação social, por sua vez, se dá num clima de tensividade, em que ocorrem discordâncias devidas a conflitos conceptuais, a choques semânticos e a diferentes propostas de visão de mundo. Em 11 de setembro de 2001, por exemplo, a humanidade presenciou um dos maiores espetáculos de mídia já produzidos e gravados na memória coletiva. A força das imagens do 
Rev. ANPOLL, n. 14, p. 57-76, jan./jun. 2003.

terror se introjeta, ainda hoje, potentemente em nossas mentes. Não é preciso grande esforço para "rever", por exercício de memória, as cenas de desespero incontido que invadiram nossos lares. Osama bin Laden declarara guerra aos Estados Unidos e, no caso das guerras, as emoções provocadas pela invocação de sentimentos ligados à família, à pátria, à justiça vão criando um inventário de paixões que, na linguagem, se transforma em movimentos argumentativos capazes de ganhar espaço na mente dos interlocutores, registrar-se na memória e produzir efeitos de sentido. Cinco dias depois do atentado, com certeza ainda sob forte impacto emocional, Carlos Heitor Cony, em sua crõnica diária na Folha de S. Paulo, num esforço para racionalizar os acontecimentos, escreveu "Momentos de História". O título já destaca a procura na memória por justificativas históricas para a crueldade vista em todos os canais de televisão do mundo:

\section{Momentos de história}

Historiadores romanos deixaram registros das primeiras perseguições aos cristāos, ainda no primeiro século da nossa era. Um deles chegou a dizer: "Nāo adianta matâ-los. Eles vāo sorrindo para o sacrificio, pois sabem que, logo em seguida, estarāo sentados junto ao trono do Deus deles."

Foi assim, entre outras causas, que o império romano começou a ruir. O cristianismo (a seita de um tal de Crestus, segundo Suetônio) minou os pilares da formidável estrutura militar, econômica e cultural da Roma imperial, dona incontestável do mundo.

Nāo estou fazendo nenhuma identidade com o recente atentado terrorista de Nova York. Há apenas alguma analogia. Também os fundamentalistas islâmicos acreditam que, morrendo numa guerra que eles acreditam santa, estāo indo diretamente para o céu de Alá.

A constante, numa e noutra circunstância, é que os impérios, quando atingem a hegemonia militar, econômica e cultural, tornados invenciveis pela tecnologia de que dispõem, sāo corroídos internamente por movimentos que alguns chamam de subversivos, e outros, de terroristas. Enfim, são minados pelas fatias da humanidade que se consideram excluidas do grande festim da vida. 
Ferreira, Luiz Antonio. Atos retóricos, terrorismo e mídia: o movimento das paixões.

Esquecemos facilmente as cenas de horror que marcaram aquela fuga dos americanos no Vietnā, quando a embaixada dos Estados Unidos foi ameaçada de invasão pelos que desejavam fugir das tropas que chegavam à capital. Os helicópteros levantavam vôo levando americanos pendurados uns nos outros. Foi uma das retiradas mais dramáticas da história.

Somemos as duas situaçōes. Os primeiros cristãos, alegres e jucundos, indo para o martírio em nome de uma causa que demoliria o império romano. Os americanos pendurados nos helicópteros, vinte séculos depois. Parece que a história tem o mau gosto de se repetir.

(Cony, Carlos Heitor. Jornal Folha de S. Paulo, 16 de setembro de 2001 , p. A2.)

Cony reflete sobre a guerra e suas conseqüências e levanta questionamentos que instauram problematicidade. Assim, o retor procura afetar a condição humana, comparar, excitar as paixões, solicitar a razão e tecer, no discurso, seu ato retórico. O auditório, no espetáculo da notícia, sente o abrandar ou o agigantar das paixões também a seu modo. Cony conhece os critêrios éticos de seu auditôrio, tem consciência dos valores diferentes que prevalecem nas sociedades provocadoras do ato retórico. O palco foram os Estados Unidos; os protagonistas, porém, vieram de outras terras. O autor inicia seu texto com a consciência de que, para mover o auditório, é preciso conhecer suas paixões, inclinações, gostos, desejos, crenças e disposições de espírito. A destruição das torres gêmeas de Nova York ainda afetava potentemente a sociedade e esse impacto funcionou como arma retórica para o orador, pois as situações retóricas são construções simbólicas da realidade: um composto de realidade objetiva mais a interpretação de quem as vivencia.

O ineditismo simbólico do atentado deu o mote para a interpretação de Cony que, em outras ocasiões, poderia ter tematizado o terror em situações, proporcionalmente, mais expressivas no plano numérico como, por exemplo, a morte diária, em todo o mundo, de 30 mil crianças famintas e com doenças provocadas pela extrema 
pobreza. Sob esse prisma, o número de crianças mortas diariamente equivale a 10 vezes o de mortos no atentado. A instância retórica (a imperfeição, revestida de certo grau de urgência), porém, determinou o conteúdo do texto e deixou o auditório passivel de ser influenciado, pois, naquele instante, todos buscavam luzes para entender o ocorrido diante de um mundo repentinamente desordenado, com verdades postas em xeque, parciais, concorrentes, contraditórias que podiam significar o que se quisesse. O espetacular atentado atualizava, com muito vigor, a necessidade de análises sobre os lugares politicos, econômicos, sociais e psicossociais das nações no mundo: o império caíra. De seu lado, o ato retórico congrega aquilo que é significativo e aquilo que significa e se traduz em assuntos e palavras.

\section{A constituição passional no texto}

Na afirmação de Meyer (1994: 258-61), a retorização é a consciência que um sujeito estabelece em si mesmo. Nesse ato, busca racionalizar os problemas e, assim, expulsar a problematicidade para fora de sua consciência,

[...] que só vê aí a sua solução e resolução. Pela paixão, o homem dá-se a si próprio razāo e justifica-se nas suas próprias justificaçōes. [...] A paixão assegura a coerência da razão, permitindo-lhe instaurar-se a si própria, recalcando o passional para fora dela através da diferença.

Assim,

[...] passa-se da emoção, que coloca o homem em prolongamento, para a paixão, quando o sujeito já não pode assumir a situaçāo e os problemas que ela levanta sem refletir expressamente sobre seus problemas.

No texto de Cony, o movimento passional é perfeitamente desenhado, justamente por tentar racionalizar a lógica da identidade 
e a lógica da diferença. No primeiro parágrafo, o cronista inicia a constituição de paixões: conclama seu leitor a aceder ao processo passional, ao colocar em jogo a calma e o temor. Diante do discurso de Cony, é impossivel não tomar partido, não ser levado pela paixão. E a consciência é entregue ao pathos que, por si, é um lugar problemático. No dizer de Meyer (1994: 9), a paixão é um lugar único, mas enigmático, em que o homem e o animal, a natureza humana e a natureza se encontram. E continua:

Ser hỉbrido, a paixão deriva simultaneamente do apetite sensivel e da representação que ele suscita, da pulsão e das emoçōes que nos fazem sentir. Mas a paixão é também aquilo que de mais individual há no individuo; ela cristaliza os conflitos do homem consigo mesmo e, desse modo, também com os outros.

Cony inicia seu texto referindo-se à antiga Roma para articular tensão, intensidade e temporalidade:

Historiadores romanos deixaram registros das primeiras perseguiçōes aos cristãos, ainda no primeiro século da nossa era. Um deles chegou a dizer: "Não adianta matá-los. Eles vāo sorrindo para o sacrificio, pois sabem que, logo em seguida, estarão sentados junto ao trono do Deus deles."

A palavra "sacrificio" já desperta os dispositivos passionais do leitor. O discurso de Cony inaugura, assim, o percurso passional do texto, ao movimentar razões, paixões e temas bem antigos, mas sempre muito vividos na história da humanidade. Contrapōe os detentores do poder ao poder das minorias. $\mathrm{E}$, nesse caso, o poder não físico dos condenados é mais forte do que o poder efetivo dos dominadores. Sua fala tem penetração imediata em três dimensōes: a cognitiva (que articula formas de saber), a pragmática (que estrutura a seqüência de ações) e a passional (que organiza os processos afetivos).

O cristianismo ganhou força em Roma já na metade do século I. Em 49, o edito do Imperador Cláudio expulsou os hebreus por 
Rev. ANPOLL, n. 14, p. 57-76, jan./jun. 2003.

gerarem tumultos, "sob o impulso de Chrestos" (como se percebe, o imperador não fazia distinção clara entre cristãos e hebreus). O esforço do imperador foi inútil: a carta de Paulo aos romanos, escrita no ano 57, dirige-se a uma comunidade já configurada, que logo depois sofreria perseguiçāo implacável de Nero. No plano das paixões, o destemor dos cristãos se opunha ao medo irracional do imperador: sem poderes terrenos, os cristāos, em menor número, incomodavam o império com suas crenças sobrenaturais. E o leitor, a partir dessa construção lingüisticamente construída, das sinalizaçōes que oferece e do contexto mostrado, inicia o procedimento de construção dos sentidos.

Aristóteles destacou - nāo por acaso no segundo livro da Retórica: a arte de persuadir por meio do discurso - a função dinâmica das paixões específicas (que introduzem mudanças em nossos juízos), o caráter situacional, prático, da afetividade, que depende do relacionamento mútuo dos individuos e do uso da palavra. Do ponto de vista das relaçōes entre pessoas, a lógica retórica é a da distância e da proximidade. Identificação e dessemelhanças são medidas por paixões comuns que são, simultaneamente, indices e parâmetros. Por paixões, rememoramos, Aristóteles entende tudo o que, acompanhado de dor e de prazer, provoca mudança potente no espírito, uma mudança capaz de alterar o julgamento proferido. Num sentindo mais amplo, por paixão entende-se tudo aquilo que afeta o gênero humano quando se perde de vista o que é genérico e essencial. A paixão representa o perigo máximo, pois é aquilo que desvia o homem do que ele substancialmente é e, ao mesmo tempo, é aquilo que há de mais individual, mais contingente. Assim se movem os homens.

No cenário criado por Cony, duas paixōes se impõem: contra o temor imperial, assoma a confiança dos cristãos. Os que se movem confiantes, ainda que em menor número, tornam-se os fortes, pois a segurança provém de uma certa superioridade tanto sobre as coisas quanto sobre as pessoas e gera um afastamento, suposto ou 
Ferreira, Luiz Antonio. Atos retóricos, terrorismo e mídia: o movimento das paixóes.

real, relativamente ao que pode ser prejudicial. Por sua vez, quem teme, teme os fortes, não os fracos. Movido pelo temor, o imperador organizava grandiosos espetáculos com o objetivo de aplacar a sede de vingança dos cidadãos romanos. Nesses eventos, os cristãos sofriam todo tipo de suplícios antes de serem assassinados. O exemplo de Roma serviu para difundir em todo o império uma espécie de palavra de ordem: "non licet esse christianos".

Muitas foram as interpretações para o ato terrorista dos fundamentalistas, mas comparar a situação dos romanos com a dos Estados Unidos parecer ser recorrente, pois foi objeto de discussão de Arbex Jr. (2002: 1-2), no prefácio à obra Showrnalismo: a noticia como espetáculo:

O ineditismo simbólico - e não a violência real - singulariza as imagens da destruição do World Trade Center. A grande "novidade" do atentado foi sua localização geopolitica, aconteceu na sede do império, não na periferia; e destruiu justamente a representaçāo arquitetônica daquilo que é mais caro à Roma contemporânea: o capital financeiro (e, de quebra, uma ala do centro administrativo do poder militar, em Washington). $O$ atentado inverteu a lógica da relação de forças, dai o seu impacto.

Para as grandes desgraças, é preciso achar um culpado. Guando o império é arranhado de alguma forma, é preciso achar ou criar os arranhadores. No ano 64, por exemplo, Roma sofreu um desastroso incêndio que se estendeu por seis dias e seis noites e destruiu 10 dos 14 bairros da cidade. Nos dias seguintes, em um clima de exasperação e de horror, começou a circular o boato de que Roma havia sido queimada por ordem do Imperador. Como a plebe se mostrasse cada vez mais ameaçadora, Nero, para aplacar o furor apaixonado de seus súditos, encontrou nos cristãos um bode expiatório. Provavelmente foi esse o início de um período de perseguições que, com poucos intervalos, viria a estender-se por cerca de três séculos em todo o Império Romano. Tudo indica que a pressão contrária só ampliou o número de cristãos. 
Rev. ANPOLL, n. 14, p. 57-76, jan./jun. 2003.

\section{A sensibilização passional}

Tensões e tragédias, perseguições e pretextos, raiva e calma movimentam o viver. Aristóteles atribuiu valor positivo à comoção trágica - a catarsis -, a purgaçāo do ânimo do espectador por efeito do balanço entre os sentimentos opostos e a comiseraçāo (eleos) e o terror (phobus), despertados pela representação das tragédias. A paixão, no entender de Meyer (1994: 15), simultaneamente sensivel e algo intelectualizável, situa-se aquém do logus e do universal: é o próprio individual, o flutuante, o sensivel. Assim, é o ponto de convergência da consciência sensivel, irrefletida, dirigida para os objetos externos e da consciência reflexiva. Cony precisa, ao refletir sobre as atitudes humanas, exteriorizar as paixões que as moveram.

Ao citar, por exemplo, o sorriso estampado no rosto dos condenados à morte e resumir a condenação com um "não adianta", mostra como os cristãos do Império Romano arranhavam, com sua fé inabalável, o discurso dominante. Com o sorriso, moviam conceitos de bem e mal, temor e confiança, bem e útil e contrapunham a lei comum a uma lei particular, de grupo, fortemente arraigada e, pelo que disse o autor, indestrutivel. E, assim, o orador reforça o medo: temos medo do ódio devorador e da cólera ferrenha, mas também tememos a resignação absoluta, a capacidade ilimitada de suportar a dor e, sobretudo, a desonra. O medo (metus) é cruel, é uma tristeza instável, nascida da idéia de uma coisa futura ou passada, de cujo desenlace duvidamos em certa medida, como bem acentua Chauí (2002: 59) ao lembrar o pensamento de Espinosa. No entanto, Aristóteles conceitua a coragem como o meio-termo entre as coisas que inspiram confiança e aquelas que inspiram medo.

As paixões humanas, como se vê, estão intimamente associadas ao prazer e ao sofrimento. No texto, a relaçāo entre os vários movimentos passionais é de superposição e não de implicação, pois o percurso passional não está na superficie textual, mas numa dimensão mais profunda, que, por ser implícita, só muito lentamente se 
Ferreira, Luiz Antonio. Atos retóricos, terrorismo e mídia: o movimento das paixōes.

revela. O leitor é levado a ativar sua memória e, nela, a descobrir um conjunto de paixões que o transformam sem, contudo, dominá-lo.

Foi assim, entre outras causas, que o império romano começou a ruir. O cristianismo minou os pilares da formidável estrutura militar, econômica e cultural da Roma Imperial, dona incontestável do mundo.

Para figurativizar a luta de um Davi contra os Golias, o autor contrapõe a coragem de uns à desorientação de outros: ao sorriso valente dos cristãos opõe-se a onipotência imperial romana. A coragem, como se sabe, é útil na guerra; a justiça o é na paz e na guerra. $O$ problema, tanto em Roma como nos Estados Unidos, é encontrar um consenso para Justiça. Talvez o fragmento de Euripedes (1966: 149) possa dar uma explicação possivel quando Medéia, na iminência de matar os filhos, exclama: "Sei que crimes vou cometer, mas a cólera é mais forte que minha vontade." Se os fundamentalistas matam por "justiça", os americanos acham "justo" vingar-se. A cólera é mais forte que a razão e o medo expõe a imagem de nossa impotência.

Os cristãos mostravam coragem porque achavam justo morrer por uma causa abraçada. Os fundamentalistas não procederam de forma diferente. O que se reforça como idéia no texto de Cony é a constatação de como os supostos superiores, em Roma, se deixaram ultrajar por homens desarmados e pacíficos. Roma se sentiu ultrajada, de alguma forma. O ultraje, segundo Aristóteles, consiste em causar dano e pena nas questões em que o paciente experimenta humilhação. No ultraje, o ultrajante visa apenas à própria satisfação. Interessante é que, para identificar Roma e Estados Unidos, o autor nega a tentativa de identificação:

Não estou fazendo nenhuma identidade com o recente atentado terrorista de Nova York. Há apenas alguma analogia. Também os fundamentalistas islâmicos acreditam que, morrendo numa guerra que eles acreditam santa, estão indo diretamente para o céu de Alá. 
Rev. ANPOLL, n. 14, p. 57-76, jan./jun. 2003.

Ora, fazer "analogia” é justamente buscar identidade de relaçōes entre os termos de dois ou mais pares, é buscar a semelhança, a similitude, a parecença entre dois elementos. Por isso, o "também" que inicia o último periodo citado denuncia a busca de identidade negada nas palavras do cronista. Seu esforço é para colocar o leitor em posição de juiz, uma vez que, embora não explicite, pratica o gênero judiciário, aquele que se volta para o passado e atua sobre valores éticos para mostrar o justo e o injusto. De algum modo, ressalta que as atitudes passionais de homens colocados em posiçōes antagônicas no que diz respeito a uma causa podem não ser nada humanas. O reforço do ethos americano, alimentado internamente durante muitos anos, é, repentinamente, destruído, simbólica e realisticamente, por dois aviōes. No plano retórico, a negação do autor é figura de presença: acentua a identificação.

Assim como os romanos em relação aos cristãos, a atitude dos fundamentalistas provocou o ódio dos americanos. O ódio, ainda segundo Aristóteles, é diferente da cólera: enquanto a cólera visa sempre uma pessoa particular, o ódio pode visar toda uma classe de pessoas. Por isso, nascem as guerras. $\mathrm{O}$ alvo da cólera americana podia ser Osama bin Laden, mas o alvo do ódio eram os fundamentalistas. A cólera, diz Aristóteles, pode curar-se com o tempo; o ódio, não. A cólera procura fazer pena; o ódio procura fazer o mal. A atitude nada humana dos fundamentalistas islâmicos causou temor. Que coisas e que pessoas tememos? - pergunta Aristóteles. Em que disposiçōes sentimos temor? O temor é uma paixāo e se configura numa espécie de pena ou de perturbação causada pela representação de um mal futuro e suscetivel de nos perder e de nos fazer sentir pena. Sim, foi exatamente assim que o povo americano se sentiu: encolerizado contra bin Laden, sentiu ódio dos fundamentalistas e de sua forma agressiva de fazer terrorismo porque, sobretudo, estavam (e estão) temerosos pelo futuro de sua nação. Tememos o que é suscetivel de nos causar penas profundas ou de nos fazer perecer, mesmo assim é preciso que esta ameaça não pareça 
FERreira, Luiz Antonio. Atos retóricos, terrorismo e mídia: o movimento das paixões.

afastada. A ameaça fundamentalista não parecia e, até hoje, não parece afastada.

A constante, numa e noutra circunstância, é que os impérios, quando atingem a hegemonia militar, econômica e cultural, tornados invenciveis pela tecnologia de que dispōem, são corroídos internamente por movimentos que alguns chamam subversivos, e outros, de terroristas.

O que é o terror? O que é terrorismo? Etimologicamente, é o modo de coagir, ameaçar ou influenciar outras pessoas, ou de impor-lhes a vontade pelo uso sistemático do terror. Terrorismo é forma de ação política que combate o poder estabelecido mediante o emprego da violência, é uma sucessão de atos de violência executados para infundir terror. No aspecto jurídico, o terrorismo se traduz por atos de violência contra pessoas, a liberdade, a propriedade, a segurança comum, a tranqüilidade pública e os poderes, responsáveis pela manutenção da ordem constitucional e pela administração pública. Osama bin Laden assume, sem dúvida, a concepção militar de terrorismo: uma sèrie atos de violência, dedicados a infundir terror por meio da eliminação das pessoas. Assim, o terrorismo tem um objetivo aparente que é a difusão do medo, mas seu propósito real é infundir uma metodologia que provoque medo de forma ativa e essencialmente torturante.

\section{A moralização passional}

Enfim, são minados pelas fatias da humanidade que se consideram excluidas do grande festim da vida.

Os atos extremados das minorias são considerados terroristas. O ato terrorista tem um objetivo: atacar. Não há inocentes, pois a "guerra" existe, e no possivel fanatismo, os terroristas estão lutando por uma causa considerada "justa". Por isso, nāo conseguem 
Rev. ANPOLL, n. 14, p. 57-76, jan./jun. 2003.

enxergar civis inocentes: para eles só há "inimigos". A súbita demonstração de vulnerabilidade do império criou um choque de expectativas e a surpresa cruenta do ataque provocou novas paixões: o desespero (desperatio - a tristeza nascida de uma coisa passada ou futura sobre a qual já não existe dúvida) e uma das espécies de amor: o patriotismo exacerbado. Os Estados Unidos, então, passaram a respirar uma opressiva atmosfera de "caça às bruxas". O atentado, dado seu caráter espetacular, atualizou, como dissemos, com força extraordinária, a necessidade de novas análises sobre o lugar político, econômico, social, cultural e psicossocial dos Estados Unidos e da mídia no mundo contemporâneo. No choque das paixões, prevaleceu o olho por olho.

Esquecemos facilmente as cenas de horror que marcaram aquela fuga dos americanos no Vietnã, quando a embaixada dos Estados Unidos foi ameaçada de invasão pelos que desejavam fugir das tropas que chegavam à capital. Os helicópteros levantavam vôo levando americanos pendurados uns nos outros. Foi uma das retiradas mais dramáticas da história.

Somemos as duas situaçōes. Os primeiros cristãos, alegres e jucundos, indo para o martírio em nome de uma causa que demoliria o império romano. Os americanos pendurados nos helicópteros, vinte séculos depois. Parece que a história tem o mau gosto de se repetir.

O autor, de novo, recorre à memória do leitor, uma memória traduzida em actio, para desvendar o ethos de americanos e fundamentalistas em uma situação conflitante. Ao explorar o gênero demonstrativo, Carlos Heitor Cony transita entre a virtude e o vício, o belo e o disforme, o elogio e a censura e, como orador, movimenta as paixões do auditório. Após a leitura, sobrepõem-se vários movimentos de sentido, todos passionais: a vergonha, a indignação, o desprezo pela forma como seres humanos resolvem suas diferenças. De algum modo, ao ressaltar o temor que advém dos atos terroristas, Cony reforça um pensamento de Aristóteles: 
FERREIRA, Luiz Antonio. Atos retóricos, terrorismo e mídia: o movimento das paixões.

[...] o temor nos torna aptos a deliberar; ora, ninguém delibera sobre questōes sem esperança. Assim, quando é melhor que os ouvintes sintam temor, é preciso pô-los nessa disposiçāo de espirito, dizendo-lhes que podem sofrer algum mal, pois outros mais fortes que eles sofreram; e mostrar-lhes que pessoas como eles sofrem ou sofreram, por parte de quem não imaginavam, essas provocaçōes e em circunstâncias que não esperavam. (Aristóteles, 2000: 35)

O texto de Cony, ato retórico estrito, coloca em xeque as relações de poder no espaço público e no espaço político. No centro do discurso, coloca o cidadão comum, o auditório de leitores, e passionaliza o choque de lógicas diferentes: a dos interesses e a dos valores. Instiga, assim, a reflexão sobre identidade e alteridade e, pelo acionar da memória, constrói um cenário retórico muito persuasivo e representativo.

As palavras de Grize (1976: VIII) traduzem o esforço acertado do cronista diante de seu público, que, atônito, luta por mover-se entre as catástrofes provocadas pelo terrorismo:

Manter um discurso junto a alguém, fazê-lo para intervir em seu julgamento e em suas atitudes, em suma, para persuadilo, ou antes, para convencê-lo, equivale, de fato a propor-lhe uma representação. Esta lhe ê destinada, o que significa que ela deve tocá-lo. Como o ouvinte está sempre situado, em sua pessoa, no mundo e nas relaçōes com aquele que fala, os elementos universais não serão os que agirão melhor e os raciocínios demonstrativos passarão freqüentemente ao segundo plano. Assim, a argumentação aproxima-se muito mais do teatro do que da geometria. Ela cria um mundo muito mais próximo do de Calderón que do de Euclides.

Há um percurso nítido de movimento passional no texto de Cony que, assim, traça um painel de paixões capaz de atingir o auditório (pathos) por meio da discussão do ethos dos envolvidos. No plano discursivo, movimenta as memórias: a semântica, a episódica, a discursiva e cria, no leitor, a nítida sensação de que não há esperança sem medo, nem medo sem esperança. 
Rev. ANPOLL, n. 14, p. 57-76, jan./jun. 2003.

\begin{abstract}
Discourses weave from a constitutive exterior - the discourse of the other - what has already been said - and work on present saying and sayings stored in memory. In this space rhetorical action takes place. This discourse work implies a move of passions which infiltrates in the deep structure of the text and through the action of the discoursive memory sustains the argumentative resources which guarantee the agreement between the locutor and the audience. In this sense in the midiatic discourse memory and actio have a fundamental role in the anatomy and in the physiology of the rhetorical act since they constitute a performatical universe which congregates in a determinated context of communication the emotive rational and historical components which are disseminated by the kinésica (way of presenting words, of making movements) as well as by the proxemica (way of promoting the interaction with space). The purpose of this study is to reflect upon the rhetorical argumentative competence in the written media and its implications with the discoursive memory, the move of passions and the terrorism.
\end{abstract}

KEYWORDS: Rhetoric, argumentation, discoursive memory, passions, terrorism.

\title{
BIBLIOGRAFIA
}

Albaladejo, Tomas. (1991) Retórica. Madri: Sintesis.

Aristóteles. (2000) Retórica das Paixōes. São Paulo: Martins Fontes.

ARBEX JR., José. (2001) Showrnalismo: a noticia como espetáculo. São Pau1o: Casa Amarela.

Barros Filho, Clóvis de (Org.). (2002) Comunicação na pólis: ensaios sobre midia e política. Petrópolis: Vozes.

BITZER, Llyod. Functional communication: a situational perspective. In: WHITE, Eugene E. (Org.). Rhetoric in transition. University Park, Penn. State: University Press, 1980.

Burke, Kenneth. (1969) A rhetoric of motives. Berkeley: Univ. California Press. CAMPBELl, Karlyn Kohrs. (1982) The rhetorical act. Belmont, Cal.: Wadsworth. 
FERREIRA, Luiz Antonio. Atos retóricos, terrorismo e mídia. o movimento das paixóes.

Certeau, Michel de. (1996) A invenção do cotidiano. Petrópolis: Vozes.

CHARTER, Roger. (1998) A aventura do livro: do leitor ao navegador. São Paulo: Unesp.

Chauí, Marilena. (2002) In: Cardoso, Sérgio. Os sentidos da paixão. São Paulo: Cia. das Letras.

EuRípedes. "Médée". In: Théatre Complet. Paris: Garnier Flammarion, v. IV.

Grize, J. B. (1976) Prefácio a Vignaux, G. Lárgumentation. Essai d'une logique discursive. Genéve: Droz.

Haldiday, Tereza Lúcia (Org.). (1988) Atos retóricos. São Paulo: Summus.

MEYER, Michel. (1994) O filósofo e as paixões. Porto: Asa.

___ (1993) Questões de retórica: linguagem, razão e sedução. Lisboa: Nova Biblioteca 70.

Marrone, Gianfranco. (1998) Estetica del telegiornale. Identità di testata e stili comunicativi. Roma: Maltemi.

Mosca, Lineide do Lago Salvador (Org.). (1997) Retóricas de ontem e hoje. São Paulo: Humanitas.

Rubin, Antonio Albino Canelas. (2002) Eleiçōes e (Idade) Midia. In: Barros Filro, Clóvis de. Comunicação na pólis. Petrópolis: Vozes.

VAN DiJK, T. A.; KINTsch, W. (1983) Strategies of discourse comprehension. New York: Academic Press. 